\title{
The molecular detection of Anaplasma phagocytophilum and Rickettsia spp. in cat and dog fleas collected from companion animals
}

\author{
Olga Pawełczyk, Marek Asman and Krzysztof Solarz
}

Department of Parasitology, Faculty of Pharmaceutical Sciences in Sosnowiec, Medical University of Silesia, Katowice, Poland

\begin{abstract}
Companion animals can be infested by various species of parasitic insects. Cat flea Ctenocephalides felis (C. felis felis) (Bouché, 1835) and dog flea Ctenocephalides canis (Curtis, 1826) belong to multihost external parasites of mammals, which most frequently occur on domestic cats Felis catus Linnaeus and dogs Canis familiaris Linnaeus. The main aim of this study was to investigate the presence of pathogens, such as Anaplasma phagocytophilum (syn. Ehrlichia phagocytophila) and Rickettsia spp., in adult C. felis and C. canis fleas. Flea sampling has been realised from January 2013 to April 2017 in veterinary clinics, animal shelters and pet grooming salons. Fleas were collected from domestic cats and dogs, directly from the pet skin or hair. Then, the DNA was isolated from a single flea by using the alkaline hydrolysis and samples were screened for the presence of pathogens using PCR method. Anaplasma phagocytophilum has occurred in $29 \%$ of examined C. felis and $16 \%$ of C. canis individuals. In turn, the prevalence of Rickettsia spp. in cat fleas population was only $3 \%$, and the dog fleas $7 \%$. The present study showed the presence of pathogenic agents in cat and dog fleas, which indicates the potential role of these insects in circulation of A. phagocytophilum and Rickettsia spp. in the natural habitat. Furthermore, exposition to these flea species, whose hosts are domestic cats and dogs, can pose a potential risk of infection for humans.
\end{abstract}

Keywords: Ctenocephalides felis, cat flea, Ctenocephalides canis, dog flea, rickettsiae, PCR

The increased mobility of both human and companion animal populations caused the spreading of many zoonotic pathogens to other areas (Bitam et al. 2010). Hematophagous arthropods, like fleas, play a significant role as vectors in this process. Fleas are obligatory external parasites and multihost insects of medical and veterinary importance (Gray et al. 2009, Torina et al. 2013). They are able to transmit pathogenic species in a variety of ways, such as blood sucking, horizontal (co-feeding), vertical and mechanical transmission or by infected excrements (Dobler and Pfeffer 2011, Brown et al. 2015, Brown and Macaluso 2016). They can be reservoirs for many bacteria, such as Yersinia pestis, Bartonella henselae, B. quintana, B. koehlerae, B. clarridgeiae, $B$. vinsonii subsp. berkhoffi, $B$. elizabethae, $B$. rochalimae, Rickettsia spp. or Francisella tularensis (see Bechah et al. 2008, Bitam et al. 2010, Víchová et al. 2018).

The presence and possibility of transmission of Anaplasma phagocytophilum, have been poorly investigated in fleas. So far, the occurrence of this rickettsia has been reported on four continents - Europe, North America, Africa and Asia, mostly in Ixodes ticks (Derdakova et al. 2003, Stańczak et al. 2004, Stuen 2007, Radzijevskaja et al. 2018, Woldehiwet 2010). This species is classified as an opportunistic pathogen, responsible for the induction of granulo- cytic anaplasmosis, a zoonotic disease causing unspecific symptoms in humans and animals (Dumler et al. 2005).

The occurrence of some species of Rickettsia was described in fleas in several European countries (Brouqui et al. 2006, Parola 2011, Hornok et al. 2014, Špitalská et al. 2015, Radzijevskaja et al. 2018, Víchová et al. 2018). Four groups belong to Rickettsia: Spotted Fever Group rickettsiae (SFG) including approximately 20 species, Typhus Group (TG) with $R$. prowazeki and $R$. typhi, the ancestral group ( $R$. canadensis and $R$. belli) and the transitional group (R. akari, R. felis and R. australis) (Wood and Artsob 2011, Radzijevskaja et al. 2018).

The most frequently occurring rickettsiae in Central Europe are species associated with mites, such as $R$. slovaca, $R$. helvetica and R. akari (Raoult and Roux 1997, Víchová et al. 2018). However, a flea-borne species, $R$. felis, which can be transmitted transovarially and transtadially within the most competent vector, cat flea, is also reported from European countries (Gilles et al. 2008, Pérez-Osorio et al. 2008, Capelli et al. 2009, Reif and Macaluso 2009, Lappin 2018).

Most rickettsial infections manifested by non-specific symptoms, such as fever, headache, myalgia, lymphadenopathy, rash; during the chronic form, patients may ex-

Address for correspondence: O. Pawełczyk, Department of Parasitology, Faculty of Pharmaceutical Sciences in Sosnowiec, Medical University of Silesia, Katowice, Poland. Address: Jedności 8, 41-218, Sosnowiec, Poland. Phone: (32) 364-11-92; E-mail: olga.pawelczyk@sum.edu.pl 
Table 1. The number and percentage of Ctenocephalides felis (Bouché, 1835) infected with Anaplasma phagocytophilum and Rickettsia spp. collected from pets in southern Poland.

\begin{tabular}{lccc}
\hline Sex & No. of studied specimens & $\begin{array}{c}\text { No. of Anaplasma } \\
\text { phagocytophilum positive } \\
\text { fleas (prevalence) }\end{array}$ & $\begin{array}{c}\text { No. of Rickettsia spp. } \\
\text { positive fleas (prevalence) }\end{array}$ \\
\hline Female & 93 & $28(30 \%)$ & $3(3 \%)$ \\
Male & 13 & $3(23 \%)$ & 0 \\
cat fleas (prevalence)
\end{tabular}

Table 2. The number and percentage of Ctenocephalides canis (Curtis, 1826) infected with Anaplasma phagocytophilum and Rickettsia spp. collected from pets in southern Poland.

\begin{tabular}{|c|c|c|c|c|}
\hline Sex & No. of studied specimens & $\begin{array}{l}\text { No. of Anaplasma } \\
\text { phagocytophilum positive } \\
\text { fleas (prevalence) }\end{array}$ & $\begin{array}{c}\text { No. of Rickettsia spp. } \\
\text { positive fleas (prevalence) }\end{array}$ & $\begin{array}{c}\text { Total no. of infected } \\
\text { dog fleas (prevalence) }\end{array}$ \\
\hline Female & 33 & $7(21 \%)$ & $2(6 \%)$ & $9(27 \%)$ \\
\hline Male & 11 & 0 & $1(9 \%)$ & $1(9 \%)$ \\
\hline Total & 44 & $7(16 \%)$ & $3(7 \%)$ & $10(23 \%)$ \\
\hline
\end{tabular}

perience cardiovascular symptoms, like perimyocarditis or endocarditis infectiosa (Raoult and Roux 1997, Portillo et al. 2015, Lindblom et al. 2016).

The aim of this study was to monitor fleas Ctenocephalides felis (Bouché, 1835), and Ctenocephalides canis (Curtis, 1826) collected from pets for the presence of $A$. phagocytophilum and Rickettsia spp.

\section{MATERIALS AND METHODS}

\section{Sampling fleas}

The collection of fleas was realised from January 2013 to April 2017 in veterinary clinics, animal shelters and pet grooming saloons located in the cities of Upper Silesia region in southern Poland, Central Europe. Fleas were collected from domestic cats and dogs, directly from the pets skin or hair. The material was conserved in plastic tubes with $70 \%$ ethyl alcohol. Then, collected fleas were determined to species and sex using stereoscopic microscope SZ-40 (Olympus, Japan), according to morphological key of Skuratowicz (1967).

\section{DNA extraction and molecular detection of pathogens}

DNA was isolated from a single flea by using the ammonia method (alkaline hydrolysis) (Rijpkema et al. 1996). Individuals were placed in separate sterile plastic tubes with $100 \mu \mathrm{l}$ of $0.7 \mathrm{M}$ $\mathrm{NH}_{4} \mathrm{OH}$. Subsequently, fleas were mechanically crushed by the homogenate CAT X 120 (Ingenieurbüro CAT, M. Zipperer GmbH, Staufen, Germany) and the samples were boiled in a heating block TB-941U (JWElectronic, Warsaw, Poland) at $100^{\circ} \mathrm{C}$ for $15 \mathrm{~min}$. Then, lids were opened and the samples were boiled at $100^{\circ} \mathrm{C}$ for $10 \mathrm{~min}$ in order to remove the ammonia. They were centrifuged for $5 \mathrm{~min}$ at $12,000 \mathrm{rpm}$ and the supernatant was transferred to a new plastic tube. The DNA concentration was measured using the Nanospectrophometer Pearl (Implen, Munich, Germany). All measurements of the DNA concentration were in ng/ul. The DNA samples were screened for the presence of pathogens using PCR method. The amplification reactions were conducted in a thermal cycler MJ Mini (BioRad, Hercules, CA, USA). A pair of primers EHR521/EHR747 specific to the gene fragment 16S rRNA (Grzeszczuk et al. 2005, Wójcik-Fatla et al. 2009) was used for detection of Anaplasma phagocytophilum. The control sample was used thanks to A. Wójcik-Fatla from the Witold Chodzko Institute of Rural Health in Lublin. The conditions of the PCR reaction were as follows: preliminary denaturation at $94^{\circ} \mathrm{C}$ for $5 \mathrm{~min}$, then denaturation at $94^{\circ} \mathrm{C}$ for $45 \mathrm{~s}$, annealing at $60^{\circ} \mathrm{C}$ for $45 \mathrm{~s}$, elongation at $72^{\circ} \mathrm{C}$ for $20 \mathrm{~s}$ and final elongation at $72^{\circ} \mathrm{C}$ for $7 \mathrm{~min}$. Forty cycles of PCR reaction were performed. For detection of Rickettsia spp., a pair of primers RpCs.877p/RpCs.1258n, specific to the gene gltA encoding citrate synthase was used (Regnery et al. 1991, Stańczak et al. 2008). Positive control of Rickettsia helvetica was kindly provided by J. Stanczak from the Department of Tropical Medicine and Parasitology from the Medical University in Gdansk. The conditions of the PCR amplification were as follows: initial denaturation at $95^{\circ} \mathrm{C}$ for $3 \mathrm{~min}$, then denaturation at $94^{\circ} \mathrm{C}$ for $20 \mathrm{~s}$, annealing at $48^{\circ} \mathrm{C}$ for $30 \mathrm{~s}$, elongation at $60^{\circ} \mathrm{C}$ for $2 \mathrm{~min}$ and final elongation at $72^{\circ} \mathrm{C}$ for $7 \mathrm{~min}$. Thirty-five cycles were performed. The PCR products were separated electrophoretically in $2 \%$ ethidium bromide-stained gels at $80 \mathrm{~V}$ for about 2 $\mathrm{h}$. Then the gels were visualised under ultraviolet light and photographed in the analyser Omega 10 (Ultra-Lum, Temecula, CA, USA). The presence of reaction products with the size of 274 base pairs (bp) for A. phagocytophilum and 381 bp for Rickettsia spp. were considered positive.

\section{Statistical analysis}

To compare the frequency of infection by A. phagocytophilum and Rickettsia spp. in examined flea samples the Yate's corrected chi-square $\left(\chi^{2}\right)$ test was used (Statistica 10.0, PL version).

\section{RESULTS}

\section{Identification fleas}

In total 155 fleas were collected from the same number of companion animals, such as domestic dogs (Canis familiaris Linnaeus) $(\mathrm{n}=89)$ and domestic cats (Felis catus Linnaeus) $(n=66)$. The morphological analysis showed species variability of collected material because four flea species were identified from collected material. The most frequent species was Ctenocephalides felis $(\sim 68 \%)$, followed by Ctenocephalides canis ( 28\%), Pulex irritans Linnaeus, 1758 (1.9\%) and Archaeopsylla erinacei (Bouché, 1835) (1.3\%). Amongst all collected fleas the majority constituted females (85\%). Males were also found, both in $C$. felis and $C$. canis populations. 


\section{Detection of pathogenic agents in fleas}

In this study all collected cat fleas (C.felis) and dog fleas (C. canis) were molecularly analysed to detect $A$. phagocytophilum and Rickettsia spp. The DNA was isolated from 150 fleas, including 106 individuals of C. felis (93 females and 13 males) and 44 of $C$. canis (33 females and 11 males). Anaplasma phagocytophilum occurred in $29 \%$ of $C$. felis individuals. The presence of this rickettsia was confirmed both in females and males of analysed cat fleas (Table 1). The prevalence of this species in $C$. canis was $16 \%$ and $A$. phagocytophilum was detected only in females (Table 2). The prevalence of Rickettsia spp. in examined C. felis population was $3 \%$ (Tab. 1). This species was more often detected in dog fleas and it accounted for 7\% (Table 2). The presence of Rickettsia spp. was found both in females and males of C. canis and C. felis.

\section{Statistical analysis}

The statistical analysis showed that cat fleas were significantly more often infected by $A$. phagocytophilum than Rickettsia spp. $\left(\chi^{2}=23 ; \mathrm{p} \leq 0.00001\right)$ (Table 1$)$. In contrast, no significant difference was observed between the number of dog fleas infected by examined species of rickettsiae $\left(\chi^{2}=3.14 ; p=0.0762\right)$ (Table 2$)$. In comparison of the two adult forms of $C$. canis, females were significantly more often infected by $A$. phagocytophilum than males $\left(\chi^{2}=21\right.$; $\mathrm{p} \leq 0.00001)$. There was no significant difference between the infection by Rickettsia spp. amongst females and males of $C$. canis $\left(\chi^{2}=0.29 ; \mathrm{p}=0.59\right)$ (Table 2$)$. In case of $C$. felis, no difference was found for both adult forms in frequency of the $A$. phagocytophilum $\left(\chi^{2}=0.92 ; p>0.34\right)$ and Rickettsia spp. infection $\left(\chi^{2}=1.35 ; \mathrm{p}>0.245\right)$ (Table 1).

\section{DISCUSSION}

In the last decades, the attention of scientists has been focused on transmission of many pathogens by arthropods, especially ticks and mosquitoes. The data about fleas and their ability to transmit infectious agents is limited. The main purpose of this study was to investigate the presence of pathogens, such as Anaplasma phagocytophilum and Rickettsia spp., in adult Ctenocephalides felis and Ctenocephalides canis fleas.

The first attempt to detect $A$. phagocytophilum in fleas was made in the USA, in species of $C$. felis collected from domestic cats, but with negative results (Lappin et al. 2006). Another study, from Portugal also did not confirm presence of $A$. phagocytophilum in this flea species (Alves et al. 2009). Torina et al. (2013) showed a low prevalence (1\%) of this rickettsia, but only in the Oriental rat flea, Xenopsylla cheopis (Rothschild, 1903). In the same study, other flea species such as Ctenocephalides canis, C. felis and Cediopsylla inaequalis (Baker), were collected from foxes Vulpes vulpes (Linnaeus) and molecularly tested, but with negative results for $A$. phagocytophilum (see Torina et al. 2013).

In our study, the occurrence of $A$. phagocytophilum was confirmed both in analysed cat and dog fleas. The prevalence of this species in case of $C$. felis was at a high level of
$29 \%$, whereas in C. canis population $16 \%$. High frequency of A. phagocytophilum in examined fleas can indicate the occurrence of many reservoirs of this species in southern Poland. Moreover, frequent detection of this rickettsia in obligatory parasites of pets, like dog and cat fleas may indicate a high risk of exposure to this pathogen both among animals and their owners in examined area and other places, where human and animal populations migrate.

Another zoonotic pathogen detected in cat and dog fleas collected from pets was Rickettsia spp. In our research, the prevalence of this pathogen was 3\% in cat and 7\% in dog fleas. According to our knowledge, fleas may take part in natural transmission of $R$. typhi and $R$. felis (see Eremeeva et al. 2008, Teoh et al. 2017), as well as $R$. rickettsii in experimental conditions (Dobler and Pfeffer 2011, Blanton and Walker 2017). A study from the Netherlands showed occurrence of Rickettsia helvetica DNA in two unknown species of fleas collected from rodents (Sprong et al. 2009). Furthermore, Hornok et al. (2014) showed the presence of this species in two females of Archaeopsylla erinacei.

Moreover, Rickettsia spp. were found in $10.8 \%$ of analysed fleas Ctenophthalmus agyrtes (Heller, 1896), C. solutus Jordan et Rothschild, 1920, C. uncinatus (Wagner, 1898) and Nosopsyllus fasciatus (Bosc, 1800) in Slovakia (Špitalská et al. 2015) and in 44\% fleas collected from rodents C. agyrtes, Ctenophthalmus assimilis (Taschenberg, 1880), Hystrichopsylla talpae (Curtis, 1826), Megabothris turbidus (Rothschild, 1909), M. walkeri (Rothschild, 1902), Palaeopsylla soricis (Dale, 1878) in Lithuania (Radzijevskaja et al. 2018). There are many studies in Europe which confirmed the presence of Rickettsia felis in fleas (Gilles et al. 2008, Pérez-Osorio et al. 2008, Capelli et al. 2009, Reif and Macaluso 2009, Gracia et al. 2015). According to our knowledge, this is the first study in Poland, which showed the presence of Rickettsia spp. in Ctenocephalides fleas.

In reference to research, which confirms the presence and possibilty of transmission other species of rickettsiae, like $R$. felis and R. typhi in fleas (Pérez-Osorio et al. 2008, Abdad et al. 2011), the vector and reservoir role of examined cat and dog fleas for A. phagocytophilum and Rickettsia spp. could be possible, however future study are required. In spite of conducted studies about transmission of pathogenic agents by fleas, our knowledge is still limited. To explain the role of C. felis and C. canis in transmission of A. phagocytophilum and Rickettsia spp., an experimental study with screening the blood of their hosts or laboratory animals should carried out.

In conclusion, the conducted study revealed the presence of Anaplasma phagocytophilum and Rickettsia spp., both in cat and dog fleas, which indicates the potential role of examined insects in circulation of these pathogens in the natural habitat. Moreover, both $C$. felis and C. canis belong to fleas with a low host specificity and they are able to bite humans, what make a potential peril of rickettsial infection.

Acknowledgments. The authors wish to thank the staff from DAWET veterinary clinic, the workers from animal shelters FAUNA from Ruda Slaska and from Sosnowiec for their support in collection of material. 


\section{REFERENCES}

Abdad M. Y., Stenos J., Graves S. 2011: Rickettsia felis, an emerging flea-transmitted human pathogen. Emerg. Hlth. Threats J. 4: 7168 .

Alves A.S., Milhano N., Santos-Silva M., Santos A.S., VilHena M., De Sousa R. 2009: Evidence of Bartonella spp., Rickettsia spp. and Anaplasma phagocytophilum in domestic, shelter and stray cat blood and fleas, Portugal. Clin. Microbiol. Infect. 15: $1-3$.

Bechah Y., Capo C., Mege J.L., Raoult D. 2008: Rickettsial diseases: from Rickettsia-arthropod relationships to pathophysiology and animal models. Future Microbiol. 3: 223-236.

Bitam I., Dittmar K., Parola P., Whiting M.F., Raoult D. 2010: Fleas and flea-borne diseases. Int. J. Infect. Dis. 14: 667-676.

Blanton L.S., Walker D.H. 2017: Flea-borne rickettsioses and rickettsiae. Am. J. Trop. Med. Hyg. 96: 53-56.

Brouqui P., Parola P., Founier P.E., Raoult D. 2006: Spotted fever rickettsioses in southern and eastern Europe. FEMS Immunol. Med. Microbiol. 49: 2-12.

Brown L.D., Christofferson R.C., Banajee K.H., Del Piero F., Foll L.D., Macaluso K.R. 2015: Cofeeding intra- and interspecific transmission of an emerging insect-borne rickettsial pathogen. Mol. Ecol. 24: 5475-5489.

Brown L.D., Macaluso K.R. 2016: Rickettsia felis, an emerging flea-borne rickettsiosis. Curr. Trop. Med. Rep. 3: 27-39.

Capelli G., Montarsi F., Porcellato E., Maioli G., Furnari C., Rinaldi L., Oliva G., Otranto D. 2009: Occurrence of Rickettsia felis in dog and cat fleas (Ctenocephalides felis) from Italy. Parasit. Vectors 2(Suppl 1): S8.

Derdakova M., Halanova M., Stanko M., Stefancikova A., Cislakova L., Peт̌ko B. 2003: Molecular evidence for Anaplasma phagocytophilum and Borrelia burgdorferi sensu lato in Ixodes ricinus ticks from eastern Slovakia. Ann. Agric. Environ. Med. 10: 269-271.

Dobler G., Pfeffer M. 2011: Fleas as parasites of the family Canidae. Parasit. Vectors 4: 139.

Dumler J.S., Choi K.S., Garcia-Garcia J.C., Barat N.S., Scorpio D.G., Garyu J.W., Grab D.J., Bakken J.S. 2005 Human granulocytic anaplasmosis and Anaplasma phagocytophilum. Emerg. Infect. Dis. 11: 1828-1834.

Eremeeva M.E., Warashina W.R., Sturgeon M.M., Buchholz A.E., Olmsted G.K., Park S.Y., Effler P.V., KarPaTHY S.E. 2008: Rickettsia typhi and R. felis in rat fleas (Xenopsylla cheopis), Oahu, Hawaii. Emerg. Infect. Dis. 14: 1613-1615.

Gilles J., Just F.T., Silaghi C., Pradel I., Passos L.M., Lengauer H., Hellmann K., Pfister, K. 2008: Rickettsia felis in fleas, Germany. Emerg. Infect. Dis. 14: 1294-1296.

Gracia M. J., Marcén J. M., Pinal R., Calvete C., Rodes D. 2015: Prevalence of Rickettsia and Bartonella species in Spanish cats and their fleas. J. Vector. Ecol. 40: 233-239

Gray J.S., Dautel H., Estrada-Peña A., Kahl O., Lindgren E. 2009: Effects of climate change on ticks and tick-borne diseases in Europe. Interdiscip. Perspect. Infect. Dis. 2009: 593232

Grzeszczuk A., Stańczak J., Pogorzelska J., ProkopowICZ D. 2005: [Diagnostics of human granulocytic anaplasmosis.] Wiad. Parazytol. 51: 109-114. (In Polish)

Hornok S., Földvári G., Rigó K., Meli M.L., Tóth M., Molnár V., Gönczi E., Farkas R., Hofmann-Lehmann R. 2014: Vector-borne agents detected in fleas of the northern white-breasted hedgehog. Vector Borne Zoonotic Dis. 14: 74-76.

LAPPIN M. R. 2018: Update on flea and tick associated diseases of cats. Vet. Parasitol. 254: 26-29.

Lappin M.R., Griffin B., Brunt J., Riley A., Burney D., Hawley J., Brewer M.M., Jensen W.A. 2006: Prevalence of Bartonella species, Haemoplasma species, Ehrlichia species, Anaplasma phagocytophilum, and Neorickettsia risticii DNA in the blood of cats and their fleas in the United States. J. Feline Med. Surg. 8: 85-90.

Lindblom A., Wallménius K., Sjöwall J., Fryland L., Wilhelmsson P., Lindgren P.E., Forsberg P., Nilsson K. 2016 : Prevalence of Rickettsia spp. in ticks and serological and clinical outcomes in tick-bitten individuals in Sweden and on the Åland Islands. PLoS ONE 11: e0166653.

PARola P. 2011: Rickettsia felis: from rare disease in the USA to a common cause of fever in sub-Saharan Africa. Clin. Microbiol. Infect. 17: 996-1000

Pérez-Osorio C.E., Zavala-Velázquez J.E., León J.J.A., Zavala-CASTRo JE. 2008: Rickettsia felis as emergent global threat for humans. Emerg. Infect. Dis. 14: 1019-1023.

Portillo A., Santibáñez S., García-Álvarez L., Palomar A. M., Oteo J. A. 2015: Rickettsioses in Europe. Microbes Infect. 17: 834-838.

Radzijevskaja J., Kaminskienė E., Lipatova I., MardoSaité-Busaitiené D., Balčiauskas L., Stanko M., PauLAUSKAS A. 2018: Prevalence and diversity of Rickettsia species in ectoparasites collected from small rodents in Lithuania. Parasit. Vectors 11: 375.

Raoult D., Roux V. 1997: Rickettsioses as paradigms of new or emerging infectious diseases. Clin. Microbiol. Rev. 10: 694-719.

Reif K. E., Macaluso K. R. 2009: Ecology of Rickettsia felis: a review. J. Med. Entomol. 46: 723-736.

Regnery R.L., Spruil C.L., Plikaytis B.D. 1991: Genotypic identification of rickettsiae and estimation of intraspecific sequences divergence for portion of two rickettsial gene. J. Bacteriol. 173: 1576-1589.

Rijpkema S., Golubić D., Molkenboer M., Verbeek-De KRUif N., Schellekens J. 1996: Identification of four genomic groups of Borrelia burgdorferi sensu lato in Ixodes ricinus ticks collected in a Lyme borreliosis endemic region of northern Croatia. Exp. Appl. Acarol. 20: 23-30.

Skuratowicz W. 1967: Part XXIX. Fleas - Siphonaptera (Aphaniptera). In: Key to the classification of Polish insects Vol. 53. Polish Entomological Society, Warsaw, pp. 26-131.

Sprong H., Wielinga P.R., Fonville M., Reusken Ch., Brandenburg A.H., Borgsteede F., GaAsenbeek C., van der GIESSEN J.W.B. 2009: Ixodes ricinus ticks are reservoir hosts for Rickettsia helvetica and potentially carry flea-borne Rickettsia species. Parasit. Vectors 2: 41.

Špitalská E., Boldiš V., MošanskÝ L., Sparagano O., StanKO M. 2015: Rickettsia species in fleas collected from small mammals in Slovakia. Parasitol. Res. 114: 4333.

Stańczak J., Gabre R. M., Kruminis-Łozowska W., RaceWiCz M., Kubica-Biernat B. 2004: Ixodes ricinus as a vector of Borrelia burgdorferi sensu lato, Anaplasma phagocytophilum and Babesia microti in urban and suburban forests. Ann. Agric. Environ. Med. 11: 109-114.

Stańczak J., Racewicz M., Michalik J., BuczeK A. 2008 Distribution of Rickettsia helvetica in Ixodes ricinus tick populations in Poland. Int. J. Med. Microbol. 298: 231-234.

Stuen S. 2007: Anaplasma phagocytophilum - the most widespread tick-borne infection in animals in Europe. Vet. Res. Commun. 31 (Suppl. 1): 79-84.

Teoh Y.T., Hit S.F., Stevenson M.A., Graves S., Rees R., Stenos J., Traub R.J. 2017: Serological evidence of exposure to Rickettsia felis and Rickettsia typhi in Australian veterinarians. Parasit. Vectors 10: 129.

Torina A., Blanda V., Antoci F., Scimeca S., D'Agostino R., Scariano E., Piazza A., Galluzzo P., Giudice E., CaraCAPPA S. 2013: A molecular survey of Anaplasma spp., Rickettsia spp., Ehrlichia canis and Babesia microti in foxes and fleas from Sicily. Transbound Emerg. Dis. 60: 125-130. 
Víchová B., Bona M., Miterpáková M., Kraljik J., Čabanová V., Nemčíková G., Hurníková Z., Oravec M. 2018: Fleas and ticks of red foxes as vectors of canine bacterial and parasitic pathogens, in Slovakia, Central Europe. Vector Borne Zoonotic Dis. 18: 11

Wójcik-Fatla A., Szymańska J., Wdowiak L., Buczek A., DutKiEwiCZ J. 2009: Coincidence of three pathogens (Borrelia burgdorferi sensu lato, Anaplasma phagocytophilum and Babe- sia microti) in Ixodes ricinus ticks in the Lublin macroregion. Ann. Agric. Environ. Med. 16: 151-158.

WoldeHiwet Z. 2010: The natural history of Anaplasma phagocytophilum. Vet. Parasitol. 167: 108-122.

Wood H., Artsoв H. 2012: Spotted fever group rickettsiae: a brief review and a Canadian perspective. Zoonoses Publ. Hlth. 59 (Suppl. 2): 65-79.

Cite this article as: Pawełczyk O., Asman M. and Solarz K. 2019: The molecular detection of Anaplasma phagocytophilum and Rickettsia spp. in cat and dog fleas collected from companion animals. Folia Parasitol. 66: 020. 